\author{
Military Technical College \\ Kobry Elkobbah, Cairo, \\ Egypt.
}

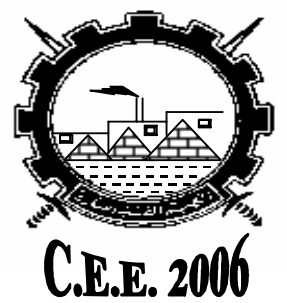

$3^{\text {rd }}$ International Conference

On

Chemical \& Environmental

Engineering

\title{
APPLLICATION OF SOME CHROMATOGRAPY TECHNIQUES IN THE ANALYSIS OF EXPLOSIVES
}

\author{
Amer A. A. ", Radwan M. A. ${ }^{*}$, Ismail M. M. ${ }^{*}$ and El-basuney Sh.
}

\begin{abstract}
Chromatographic methods, mainly TLC, HPLC, and GC, are the most common methods in the routine analysis of explosives. In this study, these techniques were used to separate and identify some of the commonly used high explosives. Standard solutions of the investigated explosives and their mixture were prepared. TLC, HPLC, and GC-MS techniques were employed to establish methods for separation and identification of the explosives. Successful separation was achieved, the minimum detection limit was determined and specific methods were established for the analysis of the used explosives.
\end{abstract}

\section{KEY WORDS}

Chromatography, TLC, HPLC, GC-MS, identification of explosives.

\section{NOMENCLATUR}

$\begin{array}{ll}\text { ACN } & \text { Acetonitrile } \\ \text { TLC } & \text { Thin layer chromatography } \\ \text { HPLC } & \text { High performance liquid chromatography } \\ \text { GC-MS } & \text { Gas chromatography - Mass spectrometry } \\ \mathrm{R}_{\mathrm{f}} & \text { Rate of flow } \\ \text { MDL } & \text { Minimum detection limit } \\ \text { mAU } & \text { milli absorbance unit } \\ \text { SPE } & \text { Solid phase extraction } \\ \text { TEA } & \text { Thermal energy analyzer } \\ \text { EI-MS } & \text { Electron ionization mass spectrometry }\end{array}$

* Egyptian Armed Force.

${ }^{* *}$ British University in Egypt (BUE). 


\section{INTRODUCTION}

Chromatography permits the separation, detection and identification of both the explosive and non explosive components of energetic materials, allowing them to be identified and compared [1-14]. During the investigation of an explosion incident, chromatography is an essential procedure used to separate trace amounts of unreacted explosives from a wide variety of sample matrices. Chromatography techniques include; Thin layer chromatograph (TLC), gas chromatography (GC), high performance liquid chromatography (HPLC), Ion chromatography (IC), Capillary electrophoresis (CE) and Supercritical fluid chromatography (SFC).

Thin layer chromatograph is one of the simplest and most widely used chromatography techniques. In thin layer chromatography the stationary phase is a powdered material adhered to a smooth support such as glass plate or aluminum sheet. Thin layer constitute the stationary phase and its nature determine the mechanism by which separation is achieved, the usual mechanism is adsorption and the common adsorbents are silica gel and aluminum oxide. HPLC can be used not only for separation but also for identification, by comparing the retention time of the unknown compound to that of a standard under the same operating conditions. However, HPLC technique can be used as qualitative and quantitative method for identification of explosives through retention time and peak area respectively. GC-MS for explosive analysis is an excellent analytical tool. It combines the strong separation power of GC and the identification power of mass spectrometry (MS).

In this paper TLC, HPLC, GC-MS techniques were employed to establish certain methods for separation and identification of the following explosives; TNT, DNT, RDX, HMX, Tetryl, NC, NG. Standard solutions of the investigated explosives and their mixtures were prepared. Chromatography techniques were employed for separation and identification of such solutions. Successful separation was achieved, the minimum detection limit were determined and specific methods were established for the analysis of the used explosives.

\section{EXPERIMENAL WORK}

Individual standard solution of each investigated explosive in acetone was prepared with concentration $1 \mathrm{mg} / \mathrm{ml}$. Another standard solution, concentration $1 \mathrm{mg}$ of each explosive/ml of solution, of a mixture containing the investigated explosives (TNT, DNT, RDX, HMX, Tetryl, PETN, NC, and NG) in acetone was prepared. This standard mixture was prepared by weighing exactly $100 \mathrm{mg}$ of each one of these explosives, and then all the samples were dissolved in $100 \mathrm{ml}$ acetone of HPLC grade. The analysis of the samples was carried out using TLC, HPLC and GC-MS.

\subsection{Application of TLC for Identification}

In TLC identification of unknown compound may be achieved by comparing rate of flow $R_{f}$ ( distance traveled by the compound /distance traveled by the developing agent) of unknown compound to that of standard on using the same experimental conditions. Identical $R_{f}$ values of two compounds, constitute the identification. Also, the color produced by the visualizing reagent is an additional feature for identification. 
Operating conditions:

Mobile phase

Stationary phase

Visualizing agent
: Toluene - Cyclohexane (7:3)

: Meric aluminum sheet coated with silica gel 60 .

: $\mathrm{NaOH} /$ Griess reagent.

It is to be noted here that, HMX, RDX, and NC couldn't be eluted by the previous mobile phase as their $R_{f}=0$. Therefore, other mobile phases were used [15].

\section{Procedures:}

1. Thin layer plate was activated at $60^{\circ} \mathrm{C}$ for 1.5 hour in an electric oven.

2. The prepared sample and standards were spotted on a line parallel to the bottom edge of the plate, at approximately $3 \mathrm{~cm}$ from the bottom.

3. The plate was placed in a vertical position in a jar saturated with mobile phase vapor pressure. The mobile phase level was below the samples level.

4. The mobile phase was allowed to travel to certain distance $R$, while sample components were eluted to different distances $r$.

5. After elution was completed the plate was removed, dried and exposed to a suitable visualizing agent, $\mathrm{NaOH} /$ Griess reagent.

\subsection{Applications of HPLC for Identification}

The used instrument was Agilent 1100 series. External standard method (EST) was employed in both qualitative and quantitative analysis for all the investigated explosives. The principle and implementation of this method are given in reference 3 and 4.

Operating conditions:

Column : $150 \mathrm{~mm}$ * $10 \mathrm{~mm}$ ld reversed phase column Zorbax SB C-18.

Mobile Phase: ACN - Water with gradient:

$$
\begin{array}{lll}
20 \% & \text { ACN } & 0: 8 \mathrm{~min} . \\
29 \% & \text { ACN } & 8.1: 35 \mathrm{~min} . \\
100 \% & \text { ACN } & 35.1: 45 \mathrm{~min} .
\end{array}
$$

Flow rate: $0.3 \mathrm{ml} / \mathrm{min}$.

Injected volume: $3 \mu \mathrm{l}$.

Detector: UV Detector at $220 \mathrm{~nm}$.

Post run: 30 minute.

Column temperature: $28^{\circ} \mathrm{C}$

It is to be mentioned here that critical pair NG and Tetryl eluted at the same retention time as NG is a good solvent for Tetryl. Thus it was difficult to be separated with high resolution. However, this problem was solved by using $40 \% \mathrm{ACN}$ as mobile phase and column temperature of $25^{\circ} \mathrm{C}$ while the other operating conditions remain the same.

\subsection{Application of GC-MS for Identification}

Gas chromatography is a well established technique in analytical and organic chemistry. The combination between the high separation power of GC and the high identification power of MS is one of the most powerful identification tool known today. 
The used GC instrument was Hewlett Packard 5890 coupled to mass selective detector (MS) 5972. The GC-MS is controlled by HP- Chemistation software.

\section{Operating conditions}

Column: Capillary column HP5MS, $30 \mathrm{~m}$ * $0.25 \mathrm{mmID}, 0.25 \mu \mathrm{m}$ film thickness.

Injection volume: $1 \mu \mathrm{L}$.

Mobile phase: Helium.

Carrier gas flow: $1 \mathrm{ml} / \mathrm{min}$.

Injection temp. : $180^{\circ} \mathrm{C}$.

Oven temp. : Oven was held at $100^{\circ} \mathrm{C}$ for $1 \mathrm{~min}$., then heated up to $300^{\circ} \mathrm{C}$ at rate of $15^{\circ} \mathrm{C} / \mathrm{min}$.

Interface temp. : $300^{\circ} \mathrm{C}$.

Ionization mode: Electron ionization (EI).

Mass Analyzer: Quadra pole mass filter.

Mass range: 50 to 600 .

Solvent delay: 3 min.

\section{RESULTS AND DISCUSSIONS}

\subsection{TLC of explosives}

TLC chromatogram of the investigated explosives is illustrated in Fig. 1. Other experimental results, rate of flow $\left(R_{f}\right)$ and minimum detection limit (MDL), are shown in Table 1. It is obvious that RDX, HMX, and NC were not eluted by the used mobile phase. Therefore, other mobile phases were used such as petrolum ether/acetone (3:1) volume ratio. Here, NC was eluted and detected easily after spraying $\mathrm{NaOH}$ and heating. But RDX and HMX still difficult to be detected because of their chemical resistance to alkaline solutions.

\subsection{HPLC of explosives}

Fig.2. illustrates an experimental HPLC chromatogram of the separated explosives. It is obvious that the samples were separated efficiently. The data analysis mode of the software was used to create a calibration table for the standard explosive mixture. Complete identification of each explosive was achieved through its retention time, name, concentration in [ng/ $\mu \mathrm{l}]$, and peak area. This calibration table was employed as an external standard (EST) for qualitative and quantitative identification. Peaks of unknown compounds were compared to that of calibration table.

The critical pair NG and tetryl were eluted together at the same retention time. Since NG is a good solvent for tetryl. To overcome this problem different mobile phase compositions were investigated. The best separation was obtained by using 40/60 $\mathrm{ACN} / \mathrm{H}_{2} \mathrm{O}$, and column temperature at $25^{\circ} \mathrm{C}$, while other operating conditions remain the same. The chromatogram of NG and tetryl is shown in Fig.3. Another method to distinguish between the critical pair NG and tetryl was achieved by changing the detector wavelength from $220 \mathrm{~nm}$ to $254 \mathrm{~nm}$, while the other operating conditions remain the same. Since NG has no absorbance at $254 \mathrm{~nm}$, while Tetryl has absorbance at this wave length, so they were distinguished just by such method. Fig. 4 shows that NG has no absorbance at $254 \mathrm{~nm}$. It is to be noted here that the peak at 1.47 is that of acetone. Fig. 5 illustrates that tetryl has absorbance at $254 \mathrm{~nm}$. 
The minimum detection limit (MDL) of the investigated explosives using HPLC technique was carried out by decreasing the solution concentration gradually. The obtained values of MDL as well as resolution are listed in Table 2. It is clear that the obtained experimental HPLC chromatogram is characterized by high resolution of separation. These experimental results demonstrate and confirm that HPLC is a useful tool in analysis and identification of explosives.

\subsection{GC-MS of explosives}

Sample identification was achieved by the obtained retention time in GC chromatograms and $\mathrm{m} / \mathrm{z}$ through Mass spectrum. These were compared to those of standard ones and database of MS spectral library. EI-MS mass spectrum of TNT is shown in Fig.6 as an example. Also, the analysis of El-MS spectra are shown in Table 3. The unknown molecule structure can be judged through mother ion, base peak, and characteristic peaks. The obtained results are in agreement with those found in literatures [2].

\section{CONCLUSIONS}

From the study the following conclusions may be withdrawn:

1. TLC technique is a fast, reliable, and non-expensive technique for detection of most of the explosives. However, fluorescent TLC plate and UV lamp $254 \mathrm{~nm}$ is recommended for RDX and HMX.

2. HPLC technique is a very useful tool in the analysis of explosives as MDL of 6 ng of some explosives was obtained.

3. GC-MS combination is a powerful separation and identification tool. However, advanced injection techniques such as on column injection, are highly recommended for thermally labile explosives such as PETN. Also, special arrangements are required for high boiling points compounds, such as HMX. 


\section{REFRENCES}

[1] Yinon J. and Zitrin S.; "The analysis of explosives", $1^{\text {st }}$ edition, Pergamon Press, Oxford, (1981).

[2] Yinon J. and Zitrin S.; "Modern methods and applications in analysis of explosives", Wiley, Chichester, (1993).

[3] Kaiser M.; "Optimization of the flow rate in high pressure liquid chromatography of explosives", Journal Propellant, Explosives and pyrotechnics; V 21, (1996).

[4] Kaiser M.; "HPLC optimization of the separation of explosives and propellant components with an octadecyl phase by computer simulation", Journal Propellant, Explosives and pyrotechnics, V 22, (1997).

[5] Nakamura J. and Ichik R. i; "Simultaneous determination of trace amounts of organic explosives and related compounds by GC-TEA", Journal - Japan explosive society 58(1), (1997).

[6] Walsh M. and Ranny T.; "Determination of nitroaromatic, nitramine, and nitrate ester explosives in water using solid phase extraction and gas chromatography-electron capture detection: comparison with high performance liquid chromatography", Journal chromatographic science $\mathrm{V} 36$, (1998).

[7] US Environmental protection agency; "Test methods for evaluating solid waste, Physical/Chemical methods. SW-846 update III", Office of solid waste, Washington DC, (1997).

[8] Anderson R.; "Sample pre-treatment and separation", John Wiley \& Sons, London, (1986).

[9] Kishi T. and Nakamura J.; "A scheme for the analysis of explosives and explosive residues in Japan", Proceeding of the 4th international symposium on analysis and detection of explosives, Kluwer academic publisher, (1992).

[10] Rubinson K. and Rubinson J.; "Contemporary instrumental analysis", Printice Hall, New York, (2000).

[11] Daniel C. H.; "Quantitative chemical analysis ", 5th edition, W.H. Freeman, New York, (1999).

[12] Shibamoto T.; "Chromatographic analysis of environmental and food toxicants", California, (1998).

[13] US Environmental protection agency; "Test methods for evaluating solid waste, Physical/Chemical methods. SW-846, Proposed draft update IVB", Office of solid waste, Washington DC, (1999).

[14] Rouessac F. and Rouessac A.;" Chemical analysis modern instrumentation methods and techniques", John willey, New York, (2000).

[15] El-basuney S. S. " Applications Of Modern Techniques used in Detection of Explosives " MSc Study, MTC, Cairo, (2004). 


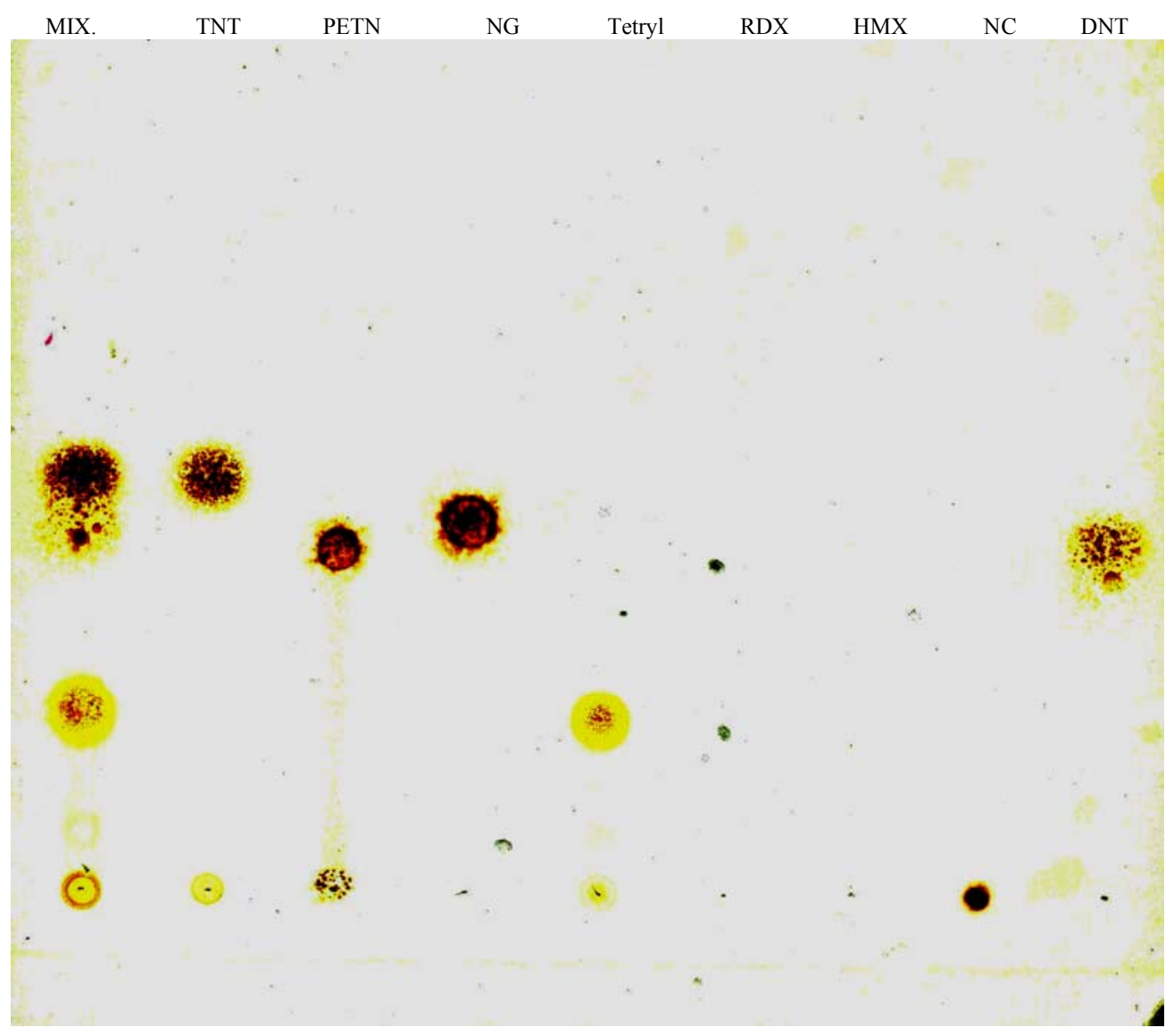

Fig.1. TLC chromatogram of the investigated explosives.

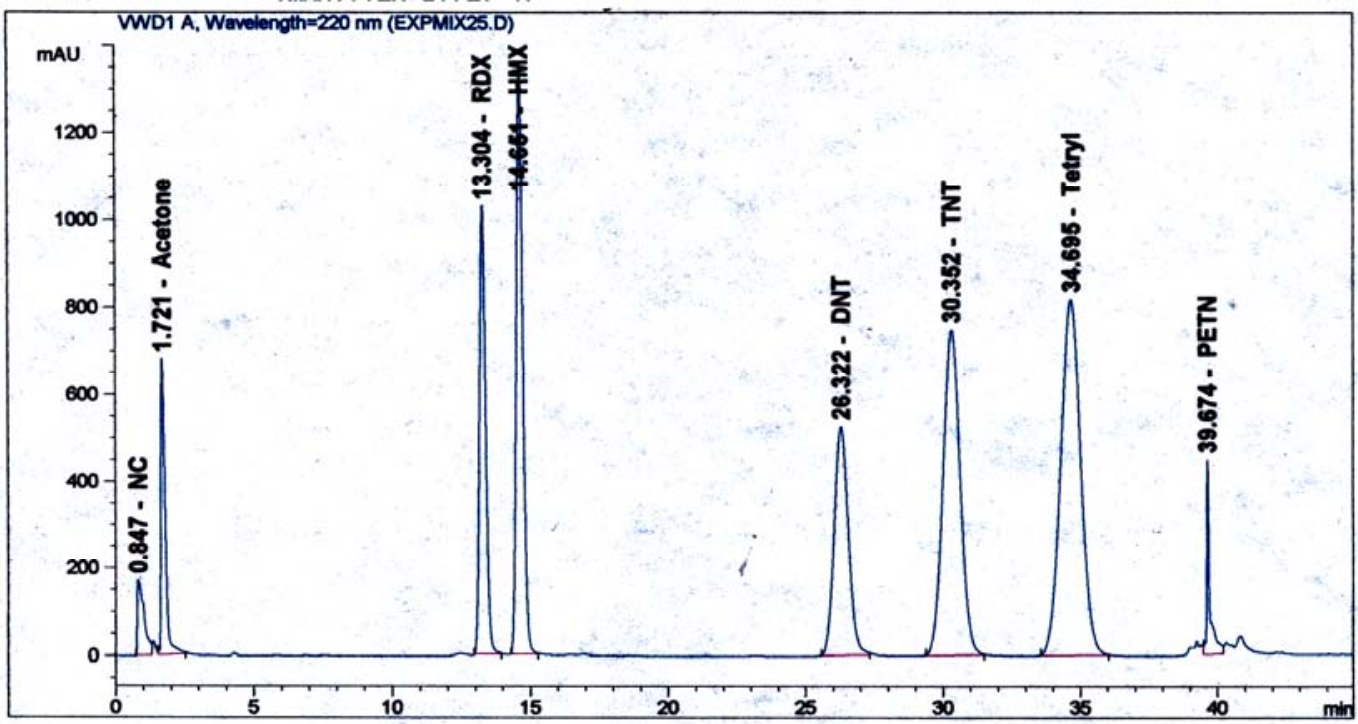

Fig.2. HPLC chromatogram of the used explosives. 


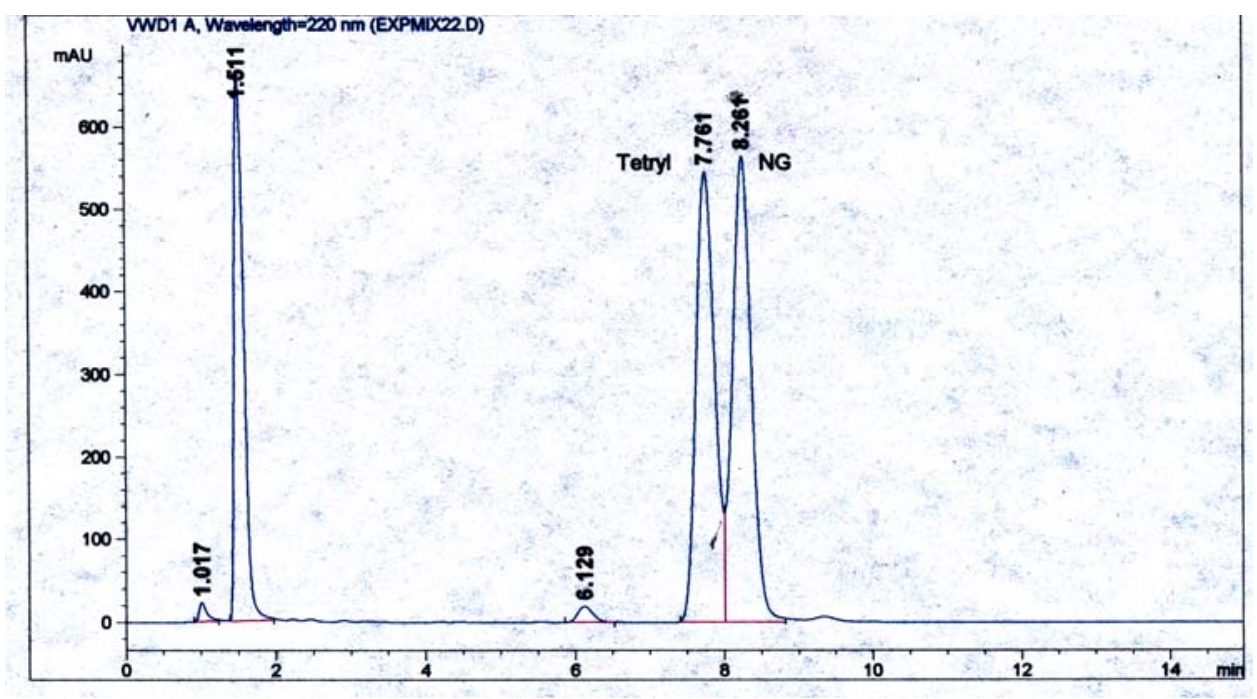

Fig. 3. HPLC chromatogram for separation of NG and Tetryl.

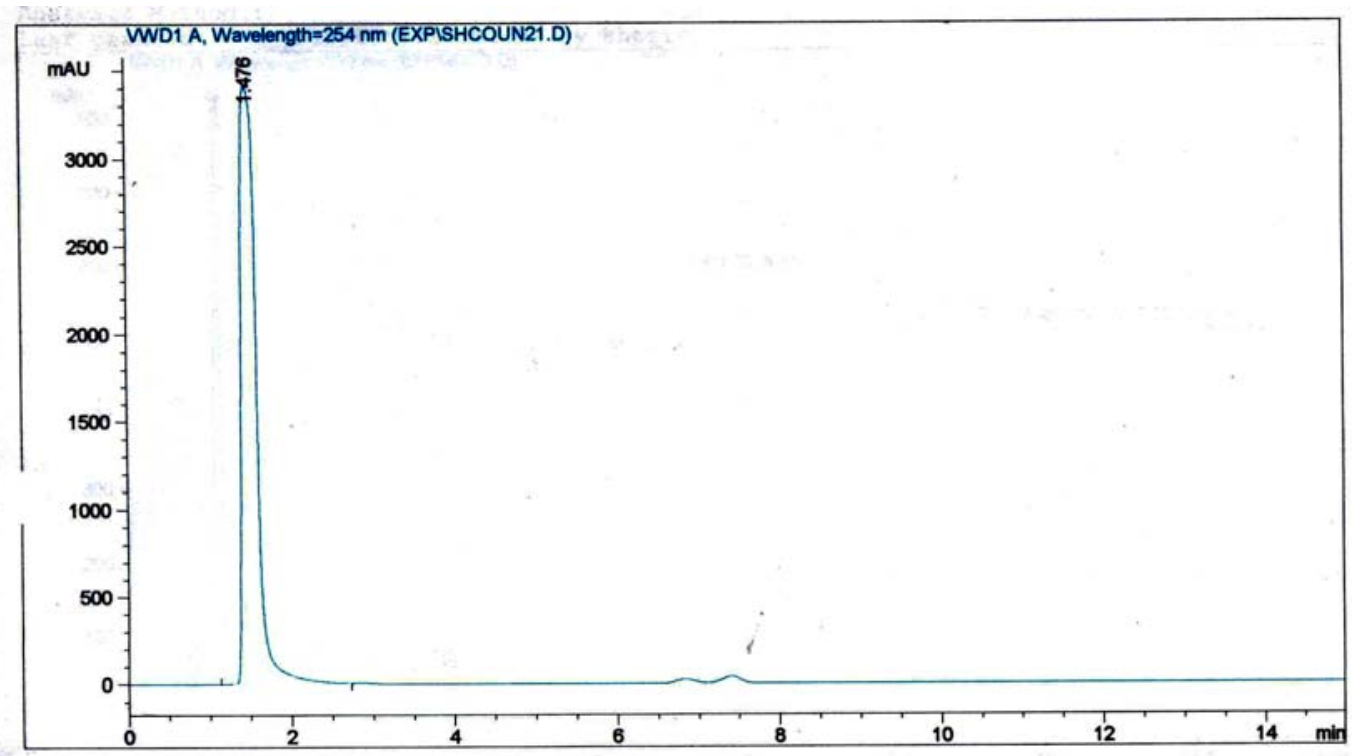

Fig. 4. HPLC output chromatogram of NG at $254 \mathrm{~nm}$. 


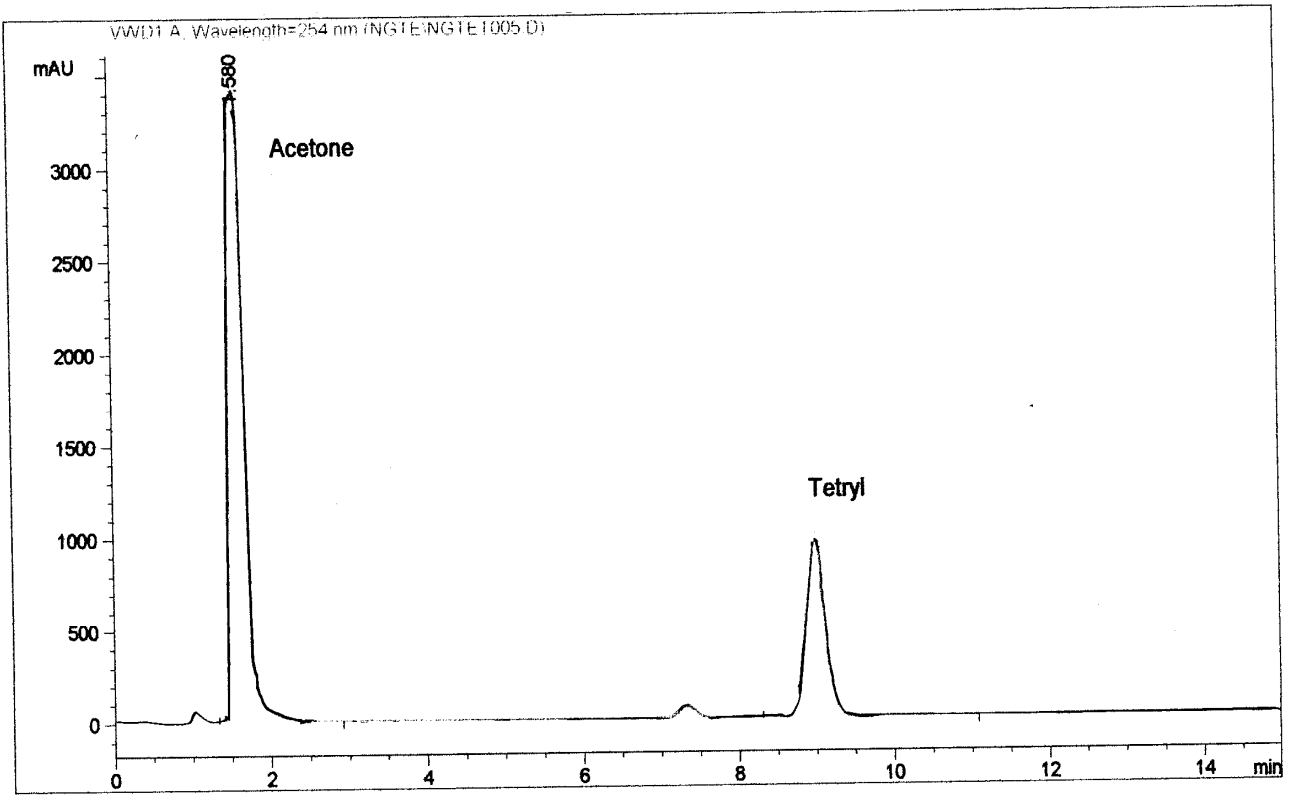

Fig.5. HPLC chromatogram of Tetryl at $254 \mathrm{~nm}$.

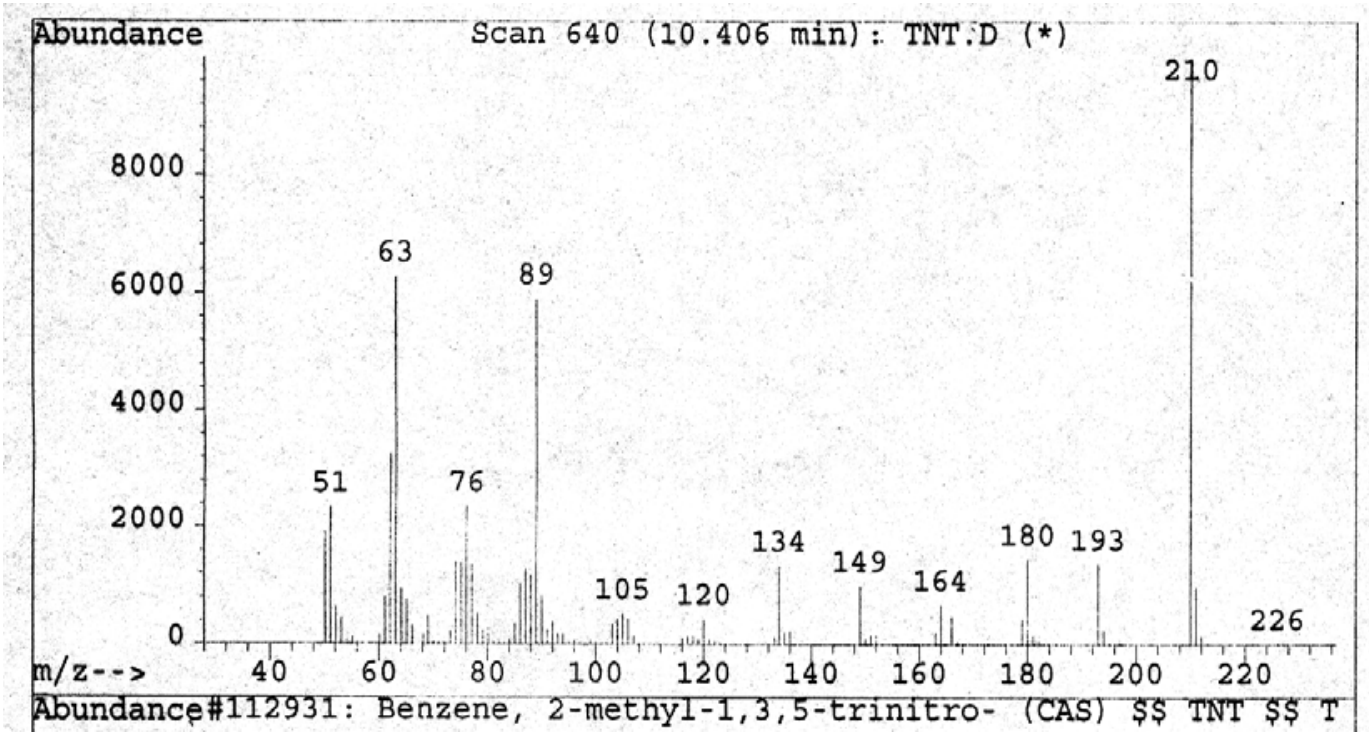

Fig.6. Experimental El-MS spectrum of TNT. 
Table 1. Characteristics of experimental TLC analysis of common explosives.

\begin{tabular}{|c|c|c|c|}
\hline No. & Explosives & Rate of flow $\left(\mathrm{R}_{\mathrm{f})}\right.$ & MDL $(\mu \mathrm{g})$ \\
\hline 1 & TNT & 0.45 & 0.7 \\
\hline 2 & DNT & 0.38 & 1.5 \\
\hline 3 & PETN & 0.37 & 3 \\
\hline 4 & NG & 0.42 & 2.5 \\
\hline 5 & Tetryl & 0.21 & 0.9 \\
\hline 6 & RDX & 0 & ---- \\
\hline 7 & HMX & 0 & ---- \\
\hline 8 & NC & 0 & 3 \\
\hline
\end{tabular}

Table 2 Minimum detection limit (MDL) and resolution of HPLC technique.

\begin{tabular}{|c|c|c|c|}
\hline No. & Explosives & MDL $(\mathrm{ng})$ & Resolution \\
\hline 1 & NC & 80 & 37 \\
\hline 2 & RDX & 6 & 37 \\
\hline 3 & HMX & 6 & 3.3 \\
\hline 4 & DNT & 22 & 17.2 \\
\hline 5 & TNT & 25 & 3.9 \\
\hline 6 & Tetryl & 32 & 3.5 \\
\hline 7 & PETN & 65 & 6.9 \\
\hline 8 & NG & 55 & 0.244 \\
\hline
\end{tabular}

Table 3. Analysis of El-MS spectra of common explosives.

\begin{tabular}{|c|c|c|c|c|c|}
\hline No. & Explosive & $\begin{array}{l}\text { Mwt. } \\
\text { g/mol }\end{array}$ & $\begin{array}{l}\text { Mother ion } \\
\text { peak } \\
\text { at } \mathrm{m} / \mathrm{z}\end{array}$ & $\begin{array}{c}\text { Base peak } \\
\text { Suggested structure } \\
\text { at } \mathrm{m} / \mathrm{z} \text { ratio }\end{array}$ & $\begin{array}{l}\text { Suggested structure at } \\
\mathrm{m} / \mathrm{z} \text { ratio }\end{array}$ \\
\hline 1 & TNT & 227 & $\begin{array}{l}{[\mathrm{M}-\mathrm{H}]^{+} \text {at }} \\
\quad 226\end{array}$ & {$[\mathrm{M}-\mathrm{OH}]^{+}$at 210} & $\begin{array}{c}{[\mathrm{M}-2 \mathrm{OH}]^{+} \text {at } 193} \\
{\left[\mathrm{M}-3 \mathrm{NO}_{2}\right]^{+} \text {at } 89} \\
{\left[\mathrm{CH}_{2} \mathrm{ONO}_{2}\right]^{+} \text {at } 76} \\
{\left[\mathrm{HONO}_{2}\right]^{+} \text {at } 63 .}\end{array}$ \\
\hline 2 & DNT & 181 & $\begin{array}{c}{[\mathrm{M}+\mathrm{H}]^{+}} \\
182\end{array}$ & {$[\mathrm{M}-\mathrm{O}]^{+}$at 165} & $\begin{array}{c}{\left[\mathrm{M}-\mathrm{CH}_{3} \mathrm{NO}_{2}\right]^{+} \text {at } 119 .} \\
{\left[\mathrm{M}-2 \mathrm{NO}_{2}\right]^{+} \text {at } 89 .} \\
{\left[\mathrm{M}-\mathrm{CH}_{3} 2(\mathrm{NO} 2)\right]^{+} \text {at78 }} \\
{\left[\mathrm{HONO}_{2}\right]^{+} \text {at } 63 .}\end{array}$ \\
\hline 3 & $\mathrm{RDX}$ & 222 & --- & {$\left[\mathrm{CH}_{3} \mathrm{~N}_{2} \mathrm{O}_{2}\right]^{+}$at 75} & $\begin{array}{c}{\left[\mathrm{M}+2 \mathrm{H}-2 \mathrm{NO}_{2}\right]^{+} \text {at } 132 .} \\
{\left[\mathrm{M}-2 \mathrm{H}-2 \mathrm{NO}_{2}\right]^{+} \text {at } 128 .} \\
{\left[\mathrm{M}+\mathrm{H}-3 \mathrm{NO}_{2}\right]^{+} \text {at } 83 .} \\
{\left[\mathrm{CH}_{2} \mathrm{CNO}\right]^{+} \text {at } 56 .}\end{array}$ \\
\hline 4 & Tetryl & 287 & --- & {$\left[\mathrm{CHNNO}_{2}\right]^{+}$at 73.} & $\begin{array}{c}{[\mathrm{M}-6 \mathrm{H}]^{+} \text {at } 281 .} \\
{[\mathrm{CNO}]^{+} \text {at } 58} \\
{\left[\mathrm{M}-5 \mathrm{H}+\mathrm{NO}_{2}\right]^{+} \text {at } 327 .} \\
{\left[\mathrm{M}-2 \mathrm{H}-3 \mathrm{NO}_{2}\right]^{+} \text {at } 147 .}\end{array}$ \\
\hline 5 & NG & 227 & --- & {$\left[\mathrm{CH}_{2} \mathrm{ONO}_{2}\right]^{+}$at 76 . } & $\begin{array}{c}{\left[\mathrm{M}-\mathrm{CH}_{3} \mathrm{OH}\right]^{+} \text {at } 207 .} \\
{\left[\mathrm{C}-\mathrm{NO}_{2}\right]^{+} \text {at } 58 .}\end{array}$ \\
\hline
\end{tabular}

